\title{
Cenários panoramáticos: um dispositivo de design estratégico em processos de diversidade cultural
}

\author{
Panoramatic scenarios: a device of strategic design in processes of cultural diversity
}

SILVA P., Claudia; Doutoranda; UNISINOS

claudiapalmadasilva@gmail.comResumo

A partir da reflexão teórica sobre linguagem, cultura, diversidade cultural, complexidade, estratégia e construção de cenários, propõem-se novos caminhos para a especulação de futuros por meio do design estratégico que destaquem, na sua centralidade, os processos culturais. Pensar cenários panoramáticos como dispositivos aproxima o design estratégico de realidades complexas, difusas e inquietas. A visão panoramática introduz ao percurso projetual a diversidade de pontos de vista, o que favorece a diversidade cultural.

Palavras Chave: cenários panoramáticos; diversidade cultural; design estratégico e narrativas digitais.

\begin{abstract}
From the theoretical reflection on language, culture, cultural diversity, complexity, strategy and scenario construction, new ways are proposed for the expectation of futures through strategic design that emphasizes cultural processes in their centrality. Thinking about panoramatic scenarios as devices approximates the strategic design of complex, diffuse and restless realities. The panoramatic view introduces to the projectual course the diversity of points of view, which favors cultural diversity.
\end{abstract}

Keywords: panoramic scenarios; cultural diversity; strategic design and digital narratives. 


\section{Introdução}

Compreender a cultura como um processo simbólico articulado por linguagens é o ponto de partida desse estudo. Esse estudo não é orientado por um problema em específico, mas propõe uma reflexão crítica de uma temática específica: a cultura - uma vez que é pertinente a diversas áreas do design, mais especificamente, do design estratégico. Partimos do pressuposto de que o designer é um articulador de linguagens e, portanto, articula as culturas por meio de suas práticas projetuais. Para Morin (2011), existe uma relação entre conhecimento, cultura e sociedade, e, portanto, faz-se necessário investigar o design nesse sentido. Para isso, é proposta, então, uma reflexão orientada pelo pensamento complexo sobre o design estratégico e diversidade cultural, visto que a realidade contemporânea apresenta-se cada vez mais complexa, difusa e inquieta.

O conceito de estratégia presente no design estratégico é, então, repensado à luz da complexidade e se aproxima do conceito de aprendizagem, afastando-se do conceito de programa pré-determinado. Isso favorece a reflexão sobre temas como a diversidade cultural, que se manifestam de forma confusa, ambígua e dinâmica e não podem ser controlados ou prédeterminados por programas. Zurlo (2010) considera que o design estratégico se ocupa, de forma geral, com o desenvolvimento de dispositivos para a transformação do mundo. Segundo Zurlo (2010), o design está situado em um âmbito coletivo e cria efeitos de sentido em uma cultura ou em uma sociedade, o que vai muito além do artefato em si. A construção de cenários é um exemplo desses dispositivos e pode ser orientada pelo pensamento complexo em processos de diversidade cultural onde o designer vai articular linguagens e, portanto, articular culturas.

As práticas de construção de cenários futuros são comuns ao design estratégico e, nesse estudo, serão ressignificadas como dispositivos que atuam por meio das diferenças culturais e mantêm os processos dialógicos em curso. Surge, então, o conceito de cenários panoramáticos, que, em síntese, são dispositivos tecnológicos que operam em sistemas abertos e colaborativos. 


\section{Pontos de partida: cultura e complexidade}

Nesse estudo, a cultura é compreendida como processo simbólico articulado pelas linguagens. Partimos de uma perspectiva segundo a qual o design é um articular de linguagens, visuais, textuais, sonoras, híbridas, digitais, entre outras - portanto, um articular da cultura. "Chamo cultura ao meio humano, tudo o que, do outro lado do cumprimento das funções biológicas, dá à vida e à atividade humana forma, sentido e conteúdo. A cultura é inerente à sociedade dos homens" (BENVENISTE, 2005, p. 31). Benveniste (2005) ainda reforça que é pela linguagem que o homem assimila a cultura, a perpetua e a transforma. Portanto, pela linguagem, o design opera e atua nas culturas e na sociedade.

As linguagens visuais, como vídeo e fotografia, ganham novas apropriações e configurações através da convergência de linguagens que surge a partir dos dispositivos tecnológicos e são de natureza digital. Assimilar esses sistemas nos leva a espaços de inventividade no design. Estudar essas linguagens exige, ainda, novas perspectivas que vão além do estruturalismo neo-saussuriano e demandam novas lentes para observar a realidade, e não somente o foco nos processos de significação.

À luz da complexidade, de acordo com Morin (2011), a compreensão da cultura parte da perspectiva de um sistema que envolve ordem-desordem e interação-organização, composta por códigos, modelos, saberes e modos de viver que não são uniformes, estanques ou sistematizados - ou, ainda, previsíveis. Esse sistema não é somente estruturado, mas complexo, desordenado e imprevisível. É a partir do caos que surgem as possibilidades de novas ordens. É pela tensão entre ordem e desordem que imaginação e inovação são potencializadas para identificação de cenários futuros. Assim, o processo simbólico é também dinâmico, imanente aos processos de transformações, os quais favorecem a interpretação dos sujeitos leitores e potencializam os sistemas de representação que são as linguagens digitais. Portanto, não podemos considerar a cultura nem mesmo como algo que é ou está, mas também como algo que está por vir, que pode ser ou resultar em, algo dinâmico e em movimento.

O mesmo autor afirma, ainda, que "a cultura que caracteriza as sociedades humanas é organizada/organizadora via o veículo cognitivo da linguagem, a partir do capital cognitivo coletivo 
dos conhecimentos adquiridos (...) em uma sociedade" (MORIN, 2011, p. 19). E, ainda, "a cultura e, via cultura, as sociedades estão no interior do conhecimento humano" (MORIN, 2011, p. 24). Desse modo, aproximar as práticas em design às práticas culturais é pensar e compreender o design também como conhecimento. Faz-se necessário destacar, então, a relação comum e indissociável entre conhecimento, cultura e sociedade proposta por Morin (2011).

Importante retomar que a complexidade é definida por Morin (2008) como um tecido (complexus: o que é tecido em conjunto) de constituintes heterogêneos inseparavelmente associados (paradoxo do uno e do múltiplo) e, ainda, como o tecido de acontecimentos, ações, interações, retroações, determinações e acasos que constituem o nosso mundo fenomenal. Para o autor, a complexidade apresenta-se com os traços inquietantes da confusão, da desordem, da ambiguidade e da incerteza. As demandas socioculturais que o design estratégico opera exigem uma visão de mundo complexa, onde a diversidade cultural é inerente à vida em sociedade. A diversidade cultural não se manifesta de forma clara, objetiva e tangível, ela é parte do tecido complexo da sociedade. As linguagens digitais, nesse estudo, são exemplos dessas manifestações complexas que podem partir de realidades difusas, inquietas e desordenadas. Essas linguagens digitais são sistemas operados por códigos que têm a capacidade de expressar relações não canônicas e não lineares. A abertura combinatória dos signos codificados digitalmente resulta em múltiplas possibilidades, o que pode fazer parte dos processos de projetação em design. A teoria da complexidade permite, então, a expansão do conhecimento nas pesquisas em que as incertezas, também, configuram o espaço da reflexão. Abre-se, aqui, a oportunidade de pensar o design no caminho entre a disciplina das soluções e a das transformações projetadas para o futuro, uma disciplina de conhecimento em uma sociedade complexa.

Através dos seus processos também dinâmicos e inquietos, o design estratégico opera nessas culturas e também é operado por essas culturas. De tal modo que, em uma relação dialógica e recursiva, esses processos não se encontram mais nas suas origens, mas nas práticas resultantes dessa relação complexa, nas quais um está no outro e o outro está no uno. É uma perspectiva que deve inspirar o design em suas práticas projetuais, que, por serem complexas, têm a potencialidade de alterar o quadro de determinismo linear por vezes dominante. 


\section{Design estratégico: um caminho não linear}

A reflexão sobre o design estratégico, orientada pelo pensamento complexo, sugere ir em direção a um pensamento que supere a perspectiva de enquadramento, de categorização e de sistematização. Desse modo, a projetação não é mais pautada somente pela necessidade de resolver problemas ou criar soluções, e isso destaca o design estratégico na sua capacidade inventiva, criativa e transformadora. Esse estudo não trabalha orientado apenas pela dicotomia de problema-solução, mas busca ir além disso: além da solução de problemas específicos, apenas, pretendendo transcender e imaginar cenários futuros não pautados exclusivamente por demandas mercadológicas lineares, mas pela diversidade cultural inerente às sociedades complexas. A linearidade do pensamento pode conduzir a um conceito reducionista da realidade, em um recorte que a divide em partes e propõe soluções pontuais, parciais. Isso pode instrumentalizar a atividade de design. Por outro lado, as perturbações e instabilidades, nesse estudo, são compreendidas como um potencial criativo. Tudo que é diferente, novo e não comum interessa em uma dimensão projetual, a fim de conduzir a proposição do novo.

O design estratégico, então, pode ser uma abordagem metodológica interessante para atender às demandas socioculturais - em especial, o tema da diversidade cultural - cada vez mais latentes. O design estratégico opera em uma dimensão metodológica orientada pela aprendizagem através da articulação de diversas disciplinas em processos transdisciplinares. Em particular, nas palavras de Zurlo (2010), o design estratégico é uma palavra-problema, um sistema aberto que inclui diversos pontos de vista, modelos interpretativos articulados e várias perspectivas disciplinares. E, ainda, o design estratégico se ocupa, de forma geral, com o desenvolvimento de dispositivos para a transformação do mundo. Segundo Zurlo (2010), o design está situado em um âmbito coletivo e cria efeitos de sentido em uma cultura ou em uma sociedade, o que vai muito além do artefato em si. A construção de cenários é um exemplo desses dispositivos e pode ser orientado pelo pensamento complexo em processos de diversidade cultural. O termo dispositivo é, então, compreendido como "qualquer coisa que tenha de algum modo a capacidade de capturar, orientar, determinar, interceptar, modelar, controlar e assegurar os gestos, as condutas, as opiniões e os discursos dos seres viventes" (AGAMBEN, 2009, p. 40). Um 
conjunto de práticas que resulta em um efeito de sentido pode, então, ser considerado um dispositivo. Portanto, não se trata apenas de algo estático ou de um artefato. O dispositivo complexo não pode ser considerado como único fator determinante, de controle exclusivo, mas um princípio que vai fomentar, orientar, movimentar um sistema, sem, com isso, que se tenha a certeza e a garantia de resultados controlados.

Outro conceito importante presente no design estratégico é a própria estratégia, que, à luz da complexidade, pode ser ampliada. Uma reflexão importante é que a estratégia é o que liberta o design de um determinismo lógico, programado e marcado pela racionalidade lógica, exclusivamente. A estratégia não é mais associada às perspectivas de controle, planejamento e previsão de resultados específicos, como nos caso das organizações tradicionais. A estratégia anda por caminhos distintos; aos programas, às ações determinadas e, ainda, a qualquer tipo de preparação que oriente para práticas e processos predeterminados. Para Morin (2008), existe uma evidente distinção entre estratégia e programa: "a estratégia permite, a partir de uma decisão inicial, encarar um certo número de cenários para a ação, cenários que poderão ser modificados segundo as informações que vão chegar no decurso da ação e segundo os imprevistos que vão surgir e perturbar a ação" (MORIN, 2008, p. 116). A ideia de programa, para o autor, não prevê mudanças nem alterações, e a ideia de estratégia integra os acasos, os acontecimentos e pode ser modificada e corrigida no percurso da ação, sem tomadas de decisões predeterminadas, como no caso do programa. Existe, assim, a partir do potencial de mudança e movimento no percurso, um aprendizado social e coletivo em dimensões socioculturais. A estratégia ganha potencialidade ao ser pensada como um processo de aprendizagem no design. Ela permite que o percurso projetual desenvolva-se no decorrer das práticas, e a construção de cenários, então, se afasta de um processo programado e se aproxima de um percurso de mudança, transformação e de inovação. Isso permite que os cenários sejam dispositivos de design em processos de diversidade cultural nos quais a realidade se apresenta cada vez mais complexa, difusa e inconstante.

Portanto, o design estratégico, por meio de dispositivos complexos de aprendizado, opera em realidades imprevisíveis, pois tem a habilidade de se movimentar conforme o decurso 
das ações. Esse percurso exige operações não lineares, que serão articuladas por meio das linguagens digitais em processos de diversidade cultural.

\section{Design e Diversidade Cultural}

A cultura, então, como proposto anteriormente, está relacionada ao conhecimento em uma sociedade na qual o design, por meio da articulação das linguagem, opera e é operado pelas culturas. O design estratégico, assim articula, por meio de suas práticas, a construção de aprendizagem sociocultural, e, desse modo, potencializa a diversidade cultural nas sociedades complexas.

A diversidade cultural pode ser compreendida como um processo inerente às culturas e não como um resultado de uma mistura ou de uma fusão cultural. O design, então, não opera com culturas distintas, mas com diversas culturas que estão em relações de coexistências/convívio que, em si, as definem. São espaços de troca e assimilação que estão em mudança, movimento, em sua totalidade. Entender que as culturas estão sempre em relação e movimento não é novo. Nesse momento, introduz-se, mais especificamente, o tema da diversidade cultural.

Morin (2011) chama a pluralidade dos pontos de vista de dialógica cultural. Isso envolve o conceito de diversidade encontrada em todas as sociedades, sejam as diferenças cognitivas entre os indivíduos, sejam as diferenças que emergem do intercâmbio de ideias entre as culturas. São processos transculturais que vão além de uma única cultura. Para que não haja um embate, uma batalha de ideias, é preciso que se estabeleça a lei do diálogo como própria regra da dialógica cultural. Morin (2011) explica ainda que, nesse processo transcultural, há um calor cultural e é importante que se estabeleça uma analogia com o conceito físico, segundo o qual onde há calor, há agitação, instabilidade e turbulência. Em um sistema cultural, esse calor pode ser oriundo de um catalisador. Sendo assim, podemos considerar que onde há calor cultural, não há determinismo, há multiplicidade, trocas, diversidade de opiniões e ideias, há movimento. Para Morin (2011), a dialógica cultural favorece o calor cultural, que, por sua vez, favorece a efervescência cultural em uma relação de totalidade. A diversidade cultural está relacionada a essa totalidade de relações complexas.

A faculdade imaginativa e criativa inerente ao design atua como uma força que mantém 
esse sistema em movimento e, ainda, que contribui para a efervescência cultural ao acolher as diferenças como elemento catalisador. Portanto, diversidade e diferença caminham juntas em um processo de inovação cultural, no qual o estranho, o diferente e o imprevisto ganham destaque. A diferença alimenta os sistemas sociais e cultiva a dialógica cultura, a efervescência e o calor cultural, em processos de estranhamento na projetação em design. Nesse estudo, as diferenças, que constituem e alimentam a diversidade em sistemas sociais, são orientadoras dos processos de design para a transformação social, por meio da articulação das linguagens e na construção de narrativas complexas. Um dos principais processos é o dialógico, uma vez que, a partir da lei do diálogo, as diferenças são postas em um sistema no qual o calor e a efervescência cultural são representados pelas diferenças de ideias e estão em uma relação de totalidade e recursividade.

Ao compreender as diferenças culturais, é preciso considerar o embate de valores e sentidos que será resultante desses processos dialógicos e que é representado através da linguagem em um percurso narrativo. Em uma perspectiva greimasiana, a noção de narrativa remonta ao nível narrativo do percurso gerativo de sentido (gerativo, no sentido estrutural), uma sucessão de ações, numa passagem de um estado anterior para um estado posterior (GREIMAS, 1973). É nas narrativas que acontecem as mudanças de estado em ações que envolvem os sujeitos e os objetos-valor. A construção de cenários em design, por exemplo, consiste em narrativas construídas por meio da articulação de linguagens visuais nos processos projetuais de design.

É possível, então, propor que o designer, através da construção de um percurso narrativo, acolha as diferenças e, assim, alimente os sistemas culturais, o que permite a criação de espaços de maior diversidade cultural em um processo transcultural, promovendo o diálogo. As linguagens digitais, por meio da codificação digital, podem representar a manifestação de realidades complexas, difusas e inquietas. Ao designer, não caberia a tarefa de interpretar, julgar, classificar ou assimilar essas linguagens, mas compreendê-las em uma dimensão projetual, como traduções de suas culturas, como articuladoras dos diálogos e como representações. Portanto, não compreendem-se as narrativas digitais como artefatos do design, como resultado ou como manifestação de design, apenas, mas como dispositivos. Operar narrativas digitais permite uma aproximação do design com uma realidade complexa e não mais estável e linear.

Além disso, importante destacar que as narrativas digitais são também visuais, e a visualidade é inerente ao design. Assim, a sua compreensão pode ser ampliada para além da 
visualidade óptica, mas na qualidade da percepção e da sensação, o que envolve outros sentidos. Findeli (2001) propõe, para o design, uma inteligência visual, aproximando os conceitos de estratégia e aprendizado, próprios do design estratégico. Essa inteligência visual, para o autor, é parte de um sistema capaz de penetrar no mundo invisível da consciência humana (pensamentos, propósitos, motivações). Esses sistemas são de complexidade semiótica, da percepção e da recepção dos artefatos de design. De um outro modo, Zurlo (2010) também destaca a visualidade e coloca as capacidades de ver, prever e fazer ver como competências de design. Para o autor, ver é a capacidade de observar os fenômenos além da sua superfície visível, é um ato criativo. A capacidade de prever é relacionada ao ver, o exercício de prever é também de dimensão criativa, que é alimentado pelo que é visto. A habilidade de fazer ver é uma ação estratégica e, portanto, de aprendizado social. É possível, então, compreender que os recursos visuais são fundamentais para que se materializem as ideias (ZURLO, 2010). Portanto, as visualidades (além da visão óptica), como as narrativas digitais, estão relacionadas às estratégias de design por meio de dispositivos. Para o mesmo autor, as novas ideias são visualizadas em diversos níveis de abstração: de uma imagem metafórica a um protótipo de trabalho. Existe, então, nessas narrativas, a capacidade de aprendizado e conhecimento que é compartilhada, de modo social e cultural.

Os cenários, enquanto dispositivos, são um caminho, uma abertura, uma construção que não envolve modelos, mas práticas, e exige mudanças comportamentais nas abordagens metodológicas orientadas pela flexibilidade e amplitude epistemológica, sem que se perca, com isso, um rigor científico para uma pesquisa em design. Promovem, assim, a aprendizagem social.

Além da proposta de Zurlo (2010), Canevacci (2001) propõe o fazer-se ver como uma ação transformadora, um processo reflexivo que envolve o sujeito em coisa que vê, no ver. Tornar-se olhos, colocando-se na posição ótica dentro dos fluxos visuais (dentro e fora ao mesmo tempo), o que significa uma atividade polimórfica, sensível e emocionada, um olhar interpretativo (CANEVACCI, 2001). Essa abordagem pode construir um percurso tanto para o pesquisador em design como para o designer, na perspectiva de que o pesquisador é parte também da cultura que observa. O fazer-se ver é um ato metaprojetual e requer um movimento, um deslocamento, por parte do designer, em relação à realidade vivida. O fazer-se ver exige o desenvolvimento de qualidades sensitivas, fundadas na percepção do olhar, na sensibilidade do ver além do sujeito em ação. 
Esse movimento será realizado nas suas práticas projetuais, como a construção de cenários, por exemplo. Para Meroni (2008), o cenário é, para o design, uma ferramenta que auxilia na visualização de futuro, de onde ir. 0 design estratégico é também a proposição de cenários futuros por meio da articulação do diálogo (MERONI, 2008).

\section{Cenários}

A metodologia que envolve a construção de cenários, tão presente nas práticas em design estratégico, que é de dimensão metaprojetual, também pode ser repensada à luz da complexidade. Esse estudo propõe repensar a metodologia de construção de cenários orientada por um novo paradigma: a complexidade. As narrativas digitais, nesse estudo, servem como subsídio para a especulação de cenários futuros em uma perspectiva sociocultural complexa, dinâmica e aberta. Com isso, o designer não vai ter o controle imediato do cenário a ser construído, mas vai operar e ser operado por ele recursivamente. Essa perspectiva ressignifica e cria um dinamismo ao conceito de cenários que autores como Moraes (2010), Manzini e Jegou (2006) propõem. Em síntese, eles compreendem cenários como a representação de futuros possíveis, a partir da articulação do presente. Segundo Moraes (2010), não se trata de prever o futuro, mas guiá-lo a partir das situações atuais. Para o autor, "o cenário existente é senão a fotografia da realidade momentânea (...) o cenário futuro pode ser percebido como antecedência (inovação) (...) e um vetor de prospecção importante" (MORAES, 2010, p. 40). 


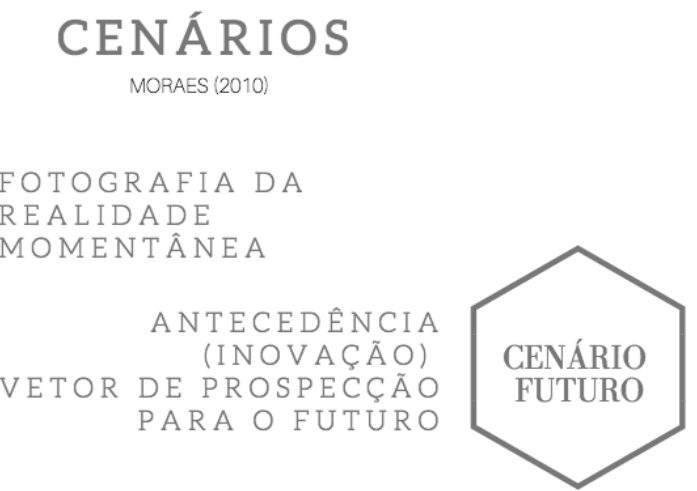

Fonte: elaboração própria com base em Moraes (2010)

É possível propor um cenário que vá além de uma fotografia, de um ponto de vista apenas. Se o pensamento projetual estiver orientado pelo pensamento complexo, a compreensão de realidade momentânea será potencializada. Será possível, então, sugerir que existem múltiplos cenários presentes e não apenas uma realidade a ser representada. Nesse caminho, a realidade manifesta-se também pela desordem, incerteza e caos. Com isso, o cenário existente vai ser desconstruído e multiplicado em novas possibilidades, e, assim, as diferenças culturais serão evidenciadas e serão catalisadoras da dialógica cultural por meio de uma ação metaprojetual. O cenário precisa, ainda, ser palco de práticas dialógicas.

Se, na construção da narrativa que constitui o cenário, o designer acolher as diferenças culturais em seu percurso, ele vai, então, manter a dialógica cultural em efervescência. Assim, essas narrativas vão orientar novas visões de futuro e permitir a especulação de realidades inovadoras e não estão mais amarradas a conceitos limitadores de uma única visão de realidade sociocultural. A narrativa digital permite, ainda, a concepção de cenários colaborativos, por meio de plataformas online, por exemplo, tema destacado por Manzini (2008) como essencial ao design. Os cenários podem ser construídos de modo colaborativo, isto é, facilitado pelas tecnologias. A tecnologia é também um dispositivo que amplia e multiplica os cenários em novos 
panoramas, novos pontos de vista. Isso favorece, por meio do design estratégico, a inovação e a

transformação do mundo.

Ao propor cenários construídos por linguagens digitais, dinâmicas e colaborativas, podemos propor dispositivos que inauguram uma nova forma de narrativa e, portanto, alteram também outras operações metodológicas que recorrem disso.

As etapas tradicionais que envolvem a construção de cenário, visão e concept são organizadas da seguinte manteira:

Figura 2 - Aplicação

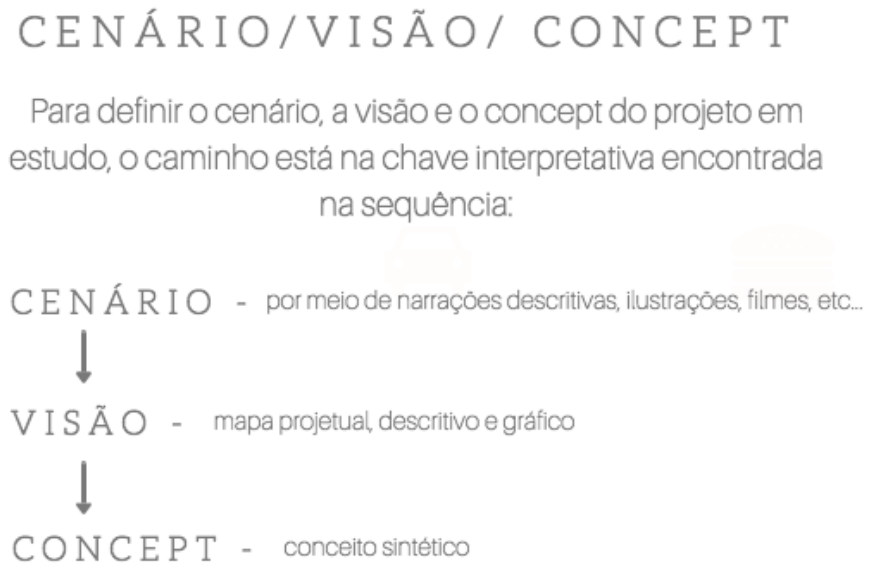

Fonte: Elaboração própria com base em Moraes (2010, p.44).

Ao considerar que os cenários podem ser dispositivos que atuam em realidades complexas, surge o conceito de cenário panoramático, que é construído por narrativas digitais complexas e permite novos panoramas, multiplica os pontos de vista e cria novos modos de ver a realidade, favorecendo, portanto, a inovação. Esses conceitos, então, podem ser reorganizados assim: 
Figura 3 - Ressignificação da aplicação de cenários de Moraes (2010):

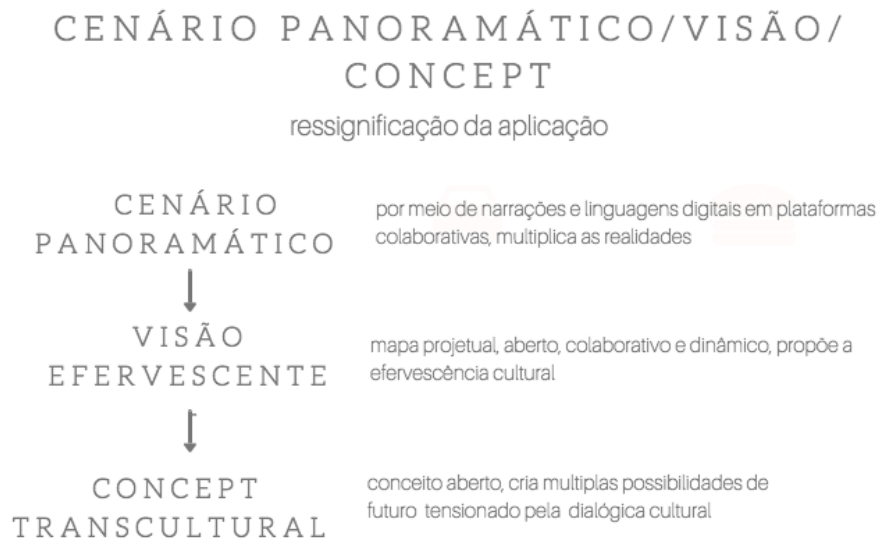

Fonte: O autor (2018)

O conceito de cenário panoramático permite, então, que o designer, em uma dimensão metaprojetual, seja um catalisador da diversidade cultural, por meio de dispositivos que acolhem as diferenças culturais e permitem a colaboração de diversos atores em plataformas digitais, em um fluxo dialógico interminável. Desse modo, os cenários panoramáticos são dispositivos de design que fazem parte dos processos de transformação do mundo. O conceito de visão é também efervescente, cria-se um mapa aberto, colaborativo, que fomenta a efervescência cultural. Além disso, o concept apresentado como etapa metaprojetual não é mais um resumo sintético, mas um conceito de múltiplas possibilidades, uma vez que é tensionado pela dialógica cultural. Cria-se uma plataforma de diálogo dinâmica e complexa, que vai ser manifestada por meio de recursos digitais, narrativas visuais e que estarão abertas e em constante processo de reconstrução.

\section{Considerações finais}

Não haveria outro modo de criar novos efeitos de sentido nas culturas senão na ação metaprojetual. De acordo com Zurlo (2010), os efeitos de sentido em uma cultura vão além do artefato em si e, portanto, exigem a produção de conhecimento que é possibilitada pela articulação de sentido nas culturas e pelas culturas. Assim como Canevacci (2001), compreendemos a narrativa visual como não linear, como artifício composto por misturas contínuas, trocas e interfaces de visões, associações e abstrações de linguagens visuais. Ao 
observar os processos de diversidade cultural inerentes a esse sistema, a partir de uma primeira síntese, é possível identificar que a diferença é um tema que pode ser acolhido pelo design em seus processos e pode, ainda, auxiliar na construção de metodologias e na construção de cenários para a projetação em design. A construção de narrativas digitais e colaborativas enaltecem as diferenças culturais, que são o elemento provocador, onde, por meio da confusão, da desordem, surgem possibilidades de novas ordens.

Para Canevacci (2001), a descentralidade do método é multiplicar o método em seu próprio agir. Nesse sentido, a capacidade do pesquisador de perder-se nas imagens e fazer-se ver é também parte do percurso metodológico. Canevacci (2001) sugere, então, a espontaneidade metodológica polifônica, o que amplia as vozes e os pontos de vista. A ressignificação do conceito de cenários para cenários panoramáticos não significa a proposição de um novo método, apenas, mas busca a reflexão das práticas a partir de novos paradigmas epistemológicos - novos no diálogo com o design, mas necessários frente aos desafios das sociedades contemporâneas. A complexidade ilumina a pesquisa em design estratégico e contribuiu para o pensamento críticoreflexivo no campo. Colocar os atores sociais em diálogo já é uma realidade possível em uma sociedade na qual a tecnologia se faz presente em todas dimensões da vida cotidiana. A ação projetual orientada por dispositivos como os cenários panoramáticos amplia esse caminho de diversidade cultural em um percurso estratégico, complexo e aberto. 


\section{Referências}

AGAMBEN, Giorgio. O que é um dispositivo. In: O que é o contemporâneo? E outros ensaios. Trad. Vinícius Nicastro Honesko. Chapecó: Argos, 2009, p. 27-51.

BENVENISTE, Émile. Problemas de Lingüística Geral I. Campinas: Pontes, 2005.

CANEVACCI, Massimo. Antropologia da Comunicação Visual. São Paulo: DP\&A Editoria, 2001.

FINDELI, A. Rethinking Design Education for the 21st Century: Theoretical, Methodological, and Ethical Discussion. Design Issues, 17(1), pp. 5-18, 2001.

GREIMAS, J. Semântica estrutural. São Paulo: Perspectiva, 1973.

MANZINI, E. (org.). Design para a Inovação Social e Sustentabilidade: Comunidades Criativas, Organizações Colaborativas e Novas Redes Projetuais. Rio de Janeiro: e-Papers, 2008.

MANZINI, E.; JÉGOU, F. Design dos cenários. In: BERTOLA, P.; MANZINI, E. Design Multiverso I Notas de fenomenologia do design. Milão: Edizioni POLI.design, 2006, pp. 189-207.

MERONI, Anna. Strategic design: where are we now? Reflection around the foundations of a recent discipline. Strategic Design Research Journal, v.1, n.1, Dec 1, p.31-38, 2008.

MORIN, E. Introdução ao pensamento complexo. Porto Alegre: Sulina, 2008.

2011.

0 método 4: as ideias: habitat, vida, costumes, organização. Porto Alegre: Sulina,

ZURLO, Francesco. Design Strategico. XXI Secolo, vol. IV, Gli spazi e le arti. Roma: Enciclopedia Treccani, 2010. 
